\title{
DILUTION OF AIRCRAFT EXHAUST PLUMES AT CRUISE ALTITUDES
}

\author{
U. SCHUMANN, ${ }^{*}$ H. SCHLAGER, F. ARNOLD, $\dagger$ R. BAUMANN, \\ P. HASCHBERGER $\$$ and O. KLEMM $\S$ \\ Deutsches Zentrum für Luft- und Raumfahrt (DLR), Institut für Physik der Atmosphäre, Oberpfaffenhofen, \\ Postfach 1116, D-82230 Wessling, Germany
}

(First received 29 April 1997 and in final form 28 September 1997. Published July 1998)

\begin{abstract}
The dilution of jet engine exhaust in the plume behind cruising aircraft is determined from measured plume properties. The data set includes in situ measurements of $\mathrm{CO}_{2}, \mathrm{NO}, \mathrm{NO}_{y}, \mathrm{SO}_{2}, \mathrm{H}_{2} \mathrm{O}$, temperature, and contrail diameters behind subsonic and supersonic aircraft in the upper troposphere and lower stratosphere, for plume ages of seconds to hours. The set of data is extended into the range of milliseconds based on computations and measured temperature values. The bulk plume dilution is expressed in terms of the dilution ratio $N$ which is the mass of air with which the exhaust from a unit mass of burned fuel mixes. For: $0.006 \mathrm{~s}<t<10^{4} \mathrm{~s}$, the bulk dilution ratio measured in more than 70 plume encounters follows approximately $N=7000\left(t / t_{0}\right)^{0.8}, t_{0}=1 \mathrm{~s}$. (C) 1998 Elsevier Science Ltd. All rights reserved
\end{abstract}

Key word index: Mixing, dispersion, aircraft emissions, jet, contrail, tropopause region.

\section{INTRODUCTION}

Aircraft cruising in the upper troposphere or lower stratosphere may impact the ozone concentration and the climatic state of the atmosphere by gaseous or particulate emissions causing a plume of exhaust species behind the aircraft (Schumann, 1994, 1997; Friedl, 1997). The impact depends on the rate of mixing of the emitted species between the plume and the ambient air. This is the case, in particular, if several simultaneously emitted species interact with each other, such as hydroxyl radicals with nitrogen and sulphuric oxides (Kärcher et al., 1996), hydroxyl radicals, oxygen radicals, soot and sulphuric gases (Arnold et al., 1994; Brown et al., 1996), and heat, water vapour, and particles causing contrails (Schumann, 1996a).

The mixing process proceeds differently in the early jet regime (Miake-Lye et al., 1993; Kärcher and Fabian, 1994), the vortex regime (Anderson et al., 1996; Schilling et al., 1996), the vortex-breakup regime (Lewellen and Lewellen, 1996; Gerz and Ehret, 1997), and the final atmospheric dispersion regime

* Author to whom correspondence should be addressed.

$\dagger$ Max-Planck-Institut für Kernphysik, Atmospheric Physics Division, 69117 Heidelberg, Germany.

†DLR, Institut für Optoelektronik, Oberpfaffenhofen, 82230 Wessling, Germany.

$\S$ Fraunhofer Gesellschaft, Institut für Atmosphärische Umweltforschung, Garmisch-Partenkirchen; now at University of Bayreuth, BITOEK Klimatologie, 95440 Bayreuth, Germany.
(Schumann et al., 1995; Dürbeck and Gerz, 1996). For consistent impact analysis one needs to know the mixing rate from the engine combuster until the plume concentration reaches the natural level of concentration fluctuations in the ambient air. For modern large subsonic aircraft, the regimes typically extend to plume ages of $10 \mathrm{~s}, 100 \mathrm{~s}, 3 \mathrm{~min}$, and $3 \mathrm{~h}$, for the jet, vortex, break-up, and dispersion regimes, respectively (Schumann et al., 1995; Gerz and Ehret, 1997).

The details of the mixing process are complex and result in a three-dimensional and time-dependent exhaust plume field. However, the plume properties may be approximated, e.g. in a box model (Karol et al., 1997), in terms of the bulk mean properties of the plume. The dilution ratio $N$ as used in this study, measures the amount of air mass with which the exhaust resulting from a unit mass of burned fuel mixes per unit flight distance within the bulk of the plume. Alternatively, one may define a dilution factor $d$ measuring the bulk plume concentration relative to the concentration at the engine exit. This value depends, however, on the air/fuel ratio within the engine and on the split of air streams in core and bypass ducts of the turbofan engines (see, e.g., Schumann, 1995).

This paper deduces the dilution ratio $N$ for a set of previous measurements. The data include measurements of conservative tracers such as carbon dioxide $\left(\mathrm{CO}_{2}\right)$ and the sum of all odd nitrogen oxides $\left(\mathrm{NO}_{y}\right)$, but also data of less conservative tracers, such as reactive nitrogen oxides $\left(\mathrm{NO}_{x}\right.$, sum of $\mathrm{NO}$ and $\left.\mathrm{NO}_{2}\right)$, and sulphur dioxide $\left(\mathrm{SO}_{2}\right)$. 


\section{PLUME DILUTION RELATIONSHIPS}

The increase in the mass specific concentration of an inert passive tracer in the plume above its ambient concentration is $\Delta c_{i}=m_{i} / m_{\text {plume }}$ for any exhaust species $i$. It depends on the mass of exhaust per unit flight distance $m_{i}$ and the mass of plume gases $m_{\text {plume }}$ per unit distance over which the exhaust gets dispersed within the plume. The mass of exhaust equals the mass of fuel burned per flight distance times the emission index of species $i, m_{i}=m_{\mathrm{fuel}} \mathrm{EI}_{i}$. The dilution ratio is defined by

$$
N=\frac{m_{\text {plume }}}{m_{\text {fuel }}}
$$

Hence, the change in mass concentration $\Delta c_{i}$ is

$$
\Delta c_{i}=\frac{\mathrm{EI}_{i}}{N} .
$$

Correspondingly, the change in volume mixing ratio $\Delta r_{i}$ of a gaseous species $i$ with molar mass $M_{i}\left(M_{\text {air }}=\right.$ $29 \mathrm{~g} \mathrm{~mole}^{-1}$ ) is

$$
\Delta r_{i}=\frac{\mathrm{EI}_{i} M_{\mathrm{air}}}{M_{i} N} .
$$

Likewise, one obtains the temperature difference between the plume and the ambient air,

$$
\Delta T=\frac{Q_{\mathrm{eff}}}{c_{p} N} .
$$

The specific heat capacity of the plume gases at constant pressure is $c_{p}=1004 \mathrm{~J} \mathrm{~kg}^{-1} \mathrm{~K}^{-1}$. The specific heat of combustion is $Q=(43.2 \pm 0.2) \mathrm{MJ} \mathrm{kg}^{-1}$ for jet aviation fuels. The effective heat release per unit fuel mass, $Q_{\text {eff }}=(1-\eta) Q$, is smaller than $Q$ depending on the overall propulsion efficiency $\eta=F V /$ $\left(Q \dot{m}_{\text {fuel }}\right)$ (Schumann, 1996a) because part of the combustion heat is used to propel the aircraft flying at speed $V$, with fuel flow rate $\dot{m}_{\text {fuel }}=V m_{\text {fuel }}$, and thrust
$F$ to produce forward motion against the aircraft's drag. This fraction of work causes heating of the air by dissipating vortex motions and turbulent motions in the far wake of the aircraft. Typically, the specific fuel consumption of modern engines at cruise is $\dot{m}_{\text {fuel }} / F=20 \mathrm{mgN}^{-1} \mathrm{~s}^{-1}$, and $\eta \cong 0.3$. The plume cross-section area and plume diameter follow from the conservation of mass,

$$
A=\frac{\pi}{4} D^{2}=\frac{\dot{m}_{\mathrm{fuel}} N}{\rho V}
$$

with $\rho$ denoting the air density within the exhaust plume.

\section{MEASURED DILUTION RATIO VALUES}

The dilution ratio $N$ can be determined from measured concentration, temperature, and plume diameter values using the above relationships. Table 1 collects data of such measurements from previous experiments. The data originate from various sources:

(1) $\mathrm{CO}_{2}$ from Schulte and Schlager (1996) (in ppmv $=\mu \mathrm{mol} \mathrm{mol}^{-1}$ ): The data given in Table 1 (No. 1.1-1.6) are the peak $\mathrm{CO}_{2}$ concentration increases as measured with a differential non-dispersive infrared instrument in-situ in the plumes of various mid-sized subsonic jet aircraft at cruise over Southern Germany near the tropopause. The emission index is known within small uncertainties based on a typical carbon mass content of $86 \%$ in the fuel.

(2) $\mathrm{CO}_{2}$ from Schulte et al. (1997): $\mathrm{CO}_{2}$ concentration was measured likewise in the plumes of various wide-body subsonic jet aircraft at cruise over the Atlantic west of Ireland near the tropopause in 1994 and 1995, between 9 and $11.2 \mathrm{~km}$ altitude.

(3) $\mathrm{CO}_{2}$ from Fahey et al. (1995a): The $\mathrm{CO}_{2}$ concentration peak values were measured in situ in the plume of a Concorde aircraft in the lower stratosphere

Table 1. Measured plume properties and dilution ratios $\left(2 . \mathrm{e} 5=2 . \times 10^{5} ; \Delta\right.$ denotes the concentration or temperature difference or the contrail diameter)

\begin{tabular}{lllrrcr}
\hline No. & Aircraft & Species & Age in s & \multicolumn{1}{c}{$\Delta$} & EI in $\mathrm{g} \mathrm{kg}^{-1}$ & $N$ \\
\hline 1.1 & MD80 & $\mathrm{CO}_{2}$ & 57 & $4.5 \mathrm{ppmv}$ & 3150 & $4.6 \mathrm{e} 5$ \\
1.2 & B727 & $\mathrm{CO}_{2}$ & 60 & $5.6 \mathrm{ppmv}$ & 3150 & $3.7 \mathrm{e} 5$ \\
1.3 & B707 & $\mathrm{CO}_{2}$ & 130 & $9.5 \mathrm{ppmv}$ & 3150 & $2.2 \mathrm{e} 5$ \\
1.4 & B737 & $\mathrm{CO}_{2}$ & 43 & $13.1 \mathrm{ppmv}$ & 3150 & $1.6 \mathrm{e} 5$ \\
1.5 & B737 & $\mathrm{CO}_{2}$ & 40 & $14.5 \mathrm{ppmv}$ & 3150 & $1.4 \mathrm{e} 5$ \\
1.6 & B737 & $\mathrm{CO}_{2}$ & 72 & $4.1 \mathrm{ppmv}$ & 3150 & $5.1 \mathrm{e} 5$ \\
2.1 & B747 & $\mathrm{CO}_{2}$ & 80 & $14.5 \mathrm{ppmv}$ & 3150 & $1.4 \mathrm{e} 5$ \\
2.2 & B747 & $\mathrm{CO}_{2}$ & 70 & $7 \mathrm{ppmv}$ & 3150 & $3.0 \mathrm{e} 5$ \\
2.3 & B747 & $\mathrm{CO}_{2}$ & 58 & $25 \mathrm{ppmv}$ & 3150 & $8.3 \mathrm{e} 5$ \\
2.4 & B747 & $\mathrm{CO}_{2}$ & 75 & $10 \mathrm{ppmv}$ & 3150 & $2.1 \mathrm{e} 5$ \\
2.5 & B747 & $\mathrm{CO}_{2}$ & 130 & $12.5 \mathrm{ppmv}$ & 3150 & $1.7 \mathrm{e} 5$ \\
2.6 & DC10 & $\mathrm{CO}_{2}$ & 90 & $5 \mathrm{ppmv}$ & 3150 & $4.2 \mathrm{e} 5$ \\
2.7 & B747 & $\mathrm{CO}_{2}$ & 100 & $25 \mathrm{ppmv}$ & 3150 & $8.3 \mathrm{e} 4$ \\
2.8 & B747 & $\mathrm{CO}_{2}$ & 75 & $7.6 \mathrm{ppmv}$ & 3150 & $2.7 \mathrm{e} 5$ \\
2.9 & B747 & $\mathrm{CO}_{2}$ & 90 & $45 \mathrm{ppmv}$ & 3150 & $4.6 \mathrm{e} 4$ \\
2.10 & A340 & $\mathrm{CO}_{2}$ & 102 & $27 \mathrm{ppmv}$ & 3150 & $7.7 \mathrm{e} 4$
\end{tabular}


Table 1. Continued.

\begin{tabular}{|c|c|c|c|c|c|c|}
\hline No. & Aircraft & Species & Age in $s$ & $\Delta$ & $\mathrm{EI}$ in $\mathrm{g} \mathrm{kg}^{-1}$ & $N$ \\
\hline 3.1 & Concorde & $\mathrm{CO}_{2}$ & 960 & $2 \mathrm{ppmv}$ & 3150 & $1.0 \mathrm{e} 6$ \\
\hline 3.2 & Concorde & $\mathrm{CO}_{2}$ & 3240 & $0.5 \mathrm{ppmv}$ & 3150 & $4.1 \mathrm{e} 6$ \\
\hline 3.3 & Concorde & $\mathrm{CO}_{2}$ & 3480 & $0.5 \mathrm{ppmv}$ & 3150 & $4.1 \mathrm{e} 6$ \\
\hline 4.1 & ER-2 & $\mathrm{CO}_{2}$ & 470 & $0.7 \mathrm{ppmv}$ & 3150 & $3.0 \mathrm{e} 6$ \\
\hline 4.2 & ER-2 & $\mathrm{CO}_{2}$ & 600 & $0.75 \mathrm{ppmv}$ & 3150 & $2.8 \mathrm{e} 6$ \\
\hline 5.1 & B747 & $\mathrm{NO}_{x}$ & 3660 & $1.81 \mathrm{ppbv}$ & 13.3 & $4.6 \mathrm{e} 6$ \\
\hline 5.2 & B767 & $\mathrm{NO}_{x}$ & 2700 & $1.67 \mathrm{ppbv}$ & 18.1 & $6.8 \mathrm{e} 6$ \\
\hline 5.3 & B747 & $\mathrm{NO}_{x}$ & 438 & $2.73 \mathrm{ppbv}$ & 18.4 & $4.2 \mathrm{e} 6$ \\
\hline 5.4 & B727 & $\mathrm{NO}_{x}$ & 5700 & $2.14 \mathrm{ppbv}$ & 7.7 & $2.2 \mathrm{e} 6$ \\
\hline 5.5 & B747 & $\mathrm{NO}_{x}$ & 1020 & $8.59 \mathrm{ppbv}$ & 19.9 & $1.46 \mathrm{e} 6$ \\
\hline 5.6 & L1011 & $\mathrm{NO}_{x}$ & 4680 & $1.03 \mathrm{ppbv}$ & 19.5 & $1.19 \mathrm{e} 7$ \\
\hline 5.7 & L1011 & $\mathrm{NO}_{x}$ & 4260 & $1.23 \mathrm{ppbv}$ & 19.6 & $1.0 \mathrm{e} 7$ \\
\hline 5.8 & B747 & $\mathrm{NO}_{x}$ & 1500 & $1.74 \mathrm{ppbv}$ & 14.8 & $5.4 \mathrm{e} 6$ \\
\hline 5.9 & B747-F & $\mathrm{NO}_{x}$ & 270 & $2.07 \mathrm{ppbv}$ & 14.8 & $4.5 \mathrm{e} 6$ \\
\hline 6.1 & B747 & $\mathrm{NO}_{y}$ & 2100 & $2.9 \mathrm{ppbv}$ & 20 & $4.3 \mathrm{e} 6$ \\
\hline 6.2 & L101 & $\mathrm{NO}_{y}$ & 2220 & $1.0 \mathrm{ppbv}$ & 20 & $1.3 \mathrm{e} 7$ \\
\hline 6.3 & B767 & $\mathrm{NO}_{y}$ & 1200 & $2.6 \mathrm{ppbv}$ & 20 & $4.8 \mathrm{e} 6$ \\
\hline 6.4 & B747 & $\mathrm{NO}_{y}$ & 1740 & 7.7 ppbv & 20 & $1.6 \mathrm{e} 6$ \\
\hline 6.5 & B747 & $\mathrm{NO}_{y}$ & 840 & $3.5 \mathrm{ppbv}$ & 20 & $3.6 \mathrm{e} 6$ \\
\hline 6.6 & A340 & $\mathrm{NO}_{y}$ & 2760 & $4.2 \mathrm{ppbv}$ & 20 & $3.0 \mathrm{e} 6$ \\
\hline 6.7 & & $\mathrm{NO}_{y}$ & 3240 & $1.0 \mathrm{ppbv}$ & 20 & $1.3 \mathrm{e} 7$ \\
\hline 6.8 & & $\mathrm{NO}_{y}$ & 3300 & $1.8 \mathrm{ppbv}$ & 20 & 7.0e6 \\
\hline 6.9 & & $\mathrm{NO}_{y}$ & 2520 & $3.3 \mathrm{ppbv}$ & 20 & $3.8 \mathrm{e} 6$ \\
\hline 6.10 & & $\mathrm{NO}_{y}$ & 4440 & $7.6 \mathrm{ppbv}$ & 20 & $1.7 \mathrm{e} 6$ \\
\hline 6.11 & & $\mathrm{NO}_{y}$ & 2520 & $4.5 \mathrm{ppbv}$ & 20 & $2.8 \mathrm{e} 6$ \\
\hline 7.1 & DC-9 & $\mathrm{SO}_{2}$ & 9 & $2.6 \mathrm{E} 10 \mathrm{~cm}^{-3}$ & 0.5 & 7.0e4 \\
\hline 7.2 & B727 & $\mathrm{SO}_{2}$ & 29 & $9 . \mathrm{E} 09 \mathrm{~cm}^{-3}$ & 0.5 & $2.0 \mathrm{e} 5$ \\
\hline 7.3 & B747 & $\mathrm{SO}_{2}$ & 44 & $1.1 \mathrm{E} 10 \mathrm{~cm}^{-3}$ & 0.5 & $1.6 \mathrm{e} 5$ \\
\hline 7.4 & B737 & $\mathrm{SO}_{2}$ & 51 & $3.0 \mathrm{E} 09 \mathrm{~cm}^{-3}$ & 0.5 & $6.0 \mathrm{e} 5$ \\
\hline 7.5 & B757 & $\mathrm{SO}_{2}$ & 68 & $3.2 \mathrm{E} 09 \mathrm{~cm}^{-3}$ & 0.5 & $5.7 \mathrm{e} 5$ \\
\hline 7.6 & B737-S & $\mathrm{SO}_{2}$ & 49 & $9.6 \mathrm{E} 09 \mathrm{~cm}^{-3}$ & 0.5 & $1.9 \mathrm{e} 5$ \\
\hline 7.7 & MD80 & $\mathrm{SO}_{2}$ & 49 & $2.0 \mathrm{E} 09 \mathrm{~cm}^{-3}$ & 0.5 & $9.1 \mathrm{e} 5$ \\
\hline 7.8 & MD80 & $\mathrm{SO}_{2}$ & 28 & $1.6 \mathrm{E} 10 \mathrm{~cm}^{-3}$ & 0.5 & $1.1 \mathrm{e} 5$ \\
\hline 7.9 & B747 & $\mathrm{SO}_{2}$ & 245 & $1.1 \mathrm{E} 10 \mathrm{~cm}^{-3}$ & 0.5 & $1.6 \mathrm{e} 5$ \\
\hline 8.1 & B747 & $\mathrm{SO}_{2}$ & 155 & $1.7 \mathrm{E} 09 \mathrm{~cm}^{-3}$ & 0.5 & $1.1 \mathrm{e} 6$ \\
\hline 8.2 & B747 & $\mathrm{SO}_{2}$ & 205 & $1.0 \mathrm{E} 09 \mathrm{~cm}^{-3}$ & 0.5 & $1.8 \mathrm{e} 6$ \\
\hline 8.3 & B747 & $\mathrm{SO}_{2}$ & 240 & $4.9 \mathrm{E} 08 \mathrm{~cm}^{-3}$ & 0.5 & $3.7 \mathrm{e} 6$ \\
\hline 8.4 & B747 & $\mathrm{SO}_{2}$ & 73 & $9.6 \mathrm{E} 09 \mathrm{~cm}^{-3}$ & 0.5 & $1.9 \mathrm{e} 5$ \\
\hline 8.5 & B747 & $\mathrm{SO}_{2}$ & 59 & $4.2 \mathrm{E} 09 \mathrm{~cm}^{-3}$ & 0.5 & $4.4 \mathrm{e} 5$ \\
\hline 8.6 & B747 & $\mathrm{SO}_{2}$ & 67 & $3.1 \mathrm{E} 09 \mathrm{~cm}^{-3}$ & 0.5 & $5.9 \mathrm{e} 5$ \\
\hline 8.7 & B747 & $\mathrm{SO}_{2}$ & 61 & $7.2 \mathrm{E} 09 \mathrm{~cm}^{-3}$ & 0.5 & $2.5 \mathrm{e} 5$ \\
\hline 8.8 & B747 & $\mathrm{SO}_{2}$ & 61 & $6.2 \mathrm{E} 09 \mathrm{~cm}^{-3}$ & 0.5 & $2.9 \mathrm{e} 5$ \\
\hline 8.9 & DC10 & $\mathrm{SO}_{2}$ & 90 & $3.6 \mathrm{E} 09 \mathrm{~cm}^{-3}$ & 0.5 & $5.9 \mathrm{e} 5$ \\
\hline 8.10 & DC10 & $\mathrm{SO}_{2}$ & 99 & $5.1 \mathrm{E} 09 \mathrm{~cm}^{-3}$ & 0.5 & $3.6 \mathrm{e} 5$ \\
\hline 8.11 & B747 & $\mathrm{SO}_{2}$ & 67 & $6.7 \mathrm{E} 09 \mathrm{~cm}^{-3}$ & 0.5 & $2.7 \mathrm{e} 5$ \\
\hline 8.12 & B747 & $\mathrm{SO}_{2}$ & 85 & $6.4 \mathrm{E} 09 \mathrm{~cm}^{-3}$ & 0.5 & $2.8 \mathrm{e} 5$ \\
\hline 8.13 & B747 & $\mathrm{SO}_{2}$ & 93 & $4.3 \mathrm{E} 09 \mathrm{~cm}^{-3}$ & 0.5 & $4.2 \mathrm{e} 5$ \\
\hline 8.14 & B747 & $\mathrm{SO}_{2}$ & 104 & $3.0 \mathrm{E} 09 \mathrm{~cm}^{-3}$ & 0.5 & $6.0 \mathrm{e} 5$ \\
\hline 9.1 & DC-9 & $\mathrm{H}_{2} \mathrm{O}$ & 9 & $100 \mathrm{mg} \mathrm{kg}^{-1}$ & 1230 & $1.3 \mathrm{e} 4$ \\
\hline 9.2 & DC-9 & $\mathrm{H}_{2} \mathrm{O}$ & 9 & $40 \mathrm{mg} \mathrm{kg}^{-1}$ & 1230 & $3.1 \mathrm{e} 4$ \\
\hline 9.3 & DC-9 & $\mathrm{H}_{2} \mathrm{O}$ & 23 & $8.3 \mathrm{mg} \mathrm{kg}^{-1}$ & 1230 & $1.47 \mathrm{e} 5$ \\
\hline 10.1 & A 310 & $\Delta T$ & 3.4 & $0.8 \mathrm{~K}$ & & $3.8 \mathrm{e} 4$ \\
\hline 10.2 & A 310 & $\Delta T$ & 23 & $0.21 \mathrm{~K}$ & & $1.76 \mathrm{e} 5$ \\
\hline 10.3 & ATTAS & $\Delta T$ & 0.47 & $9.5 \mathrm{~K}$ & & 3700 \\
\hline 10.4 & ATTAS & $\Delta T$ & 0.69 & $6 \mathrm{~K}$ & & 5900 \\
\hline 11.1 & ATTAS & $\Delta T$ & 0.006 & $380 \mathrm{~K}$ & & 94 \\
\hline 12.1 & ATTAS & $D$ & 0.061 & $1.6 \mathrm{~m}$ & & 860 \\
\hline 12.2 & ATTAS & $D$ & 0.117 & $2.2 \mathrm{~m}$ & & 1620 \\
\hline 12.3 & ATTAS & $D$ & 0.117 & $2.1 \mathrm{~m}$ & & 1500 \\
\hline 12.4 & ATTAS & $D$ & 0.184 & $2.8 \mathrm{~m}$ & & 2600 \\
\hline 12.5 & ATTAS & $D$ & 0.184 & $2.2 \mathrm{~m}$ & & 1600 \\
\hline 12.6 & ATTAS & $D$ & 0.37 & $3.3 \mathrm{~m}$ & & 3700 \\
\hline 12.7 & ATTAS & $D$ & 0.37 & $3.0 \mathrm{~m}$ & & 3000 \\
\hline 12.8 & ATTAS & $D$ & 0.55 & $4.1 \mathrm{~m}$ & & 5600 \\
\hline 12.9 & ATTAS & $D$ & 0.55 & $3.2 \mathrm{~m}$ & & 3440 \\
\hline
\end{tabular}


at about $16 \mathrm{~km}$ altitude over the Pacific near New Zealand, for three plume encounters.

(4) $\mathrm{CO}_{2}$ from Fahey et al. (1995b): The stratospheric research aircraft ER-2 measured its own plume at an altitude of about $20 \mathrm{~km}$ in the lower stratosphere. The peak $\mathrm{CO}_{2}$ values are available for 2 encounters.

(5) $\mathrm{NO}_{x}$ from Schlager et al. (1994) (in ppbv $=$ nmol mol ${ }^{-1}$ ): The measurements provided averaged NO increases in the plume of various subsonic airliner/engine combinations of known type at cruise. The measurements were performed using a chemiluminescence detector at $9.4-11.3 \mathrm{~km}$ altitude with the DLR Falcon research aircraft west of Scotland over the Atlantic near the tropopause. From the measured $\mathrm{NO}$ values, the $\mathrm{NO}_{x}$ concentration increase was computed assuming photochemical equilibrium. The plume age (up to $95 \mathrm{~min}$ ) is determined based on Radar observations. For such plume ages, less than $10 \%$ of the $\mathrm{NO}_{x}$ is converted to $\mathrm{NO}_{y}$ so that $\mathrm{NO}_{x}$ may be considered as a conservative tracer (Arnold et al., 1992; Karol et al., 1997). The emission indices were computed for the given engine conditions. Schumann et al. (1995) tabulated the integral $I$ of the concentration measured within the plume, the Gaussian plume width $\sigma_{f}$, and the ratio $\alpha$ of $\mathrm{NO} / \mathrm{NO}_{x}$ mixing ratios. The bulk mean plume mixing ratio is computed from $\Delta r_{\mathrm{NO}_{2}}=I /\left(2 \sigma_{f} \alpha\right)$.

(6) $\mathrm{NO}_{y}$ from Klemm et al. (1996): $\mathrm{NO}_{y}$ was measured using chemiluminescence detectors with a catalytic converter at the inlet. The measurements were performed during plume encounters of wide-body jet airliners over the North Atlantic west of Ireland in July, August, and November, 1994, at altitudes of $10.1-11.3 \mathrm{~km}$. The plume age is determined based on Radar observations (the aircraft type could not be determined for entries 6.7-6.11). The dilution ratio is computed using an estimated emission index of $20 \mathrm{~g} / \mathrm{kg}$ for $\mathrm{NO}_{x}$ (and hence, $\mathrm{NO}_{y}$ ).

(7) $\mathrm{SO}_{2}$ from Arnold et al. (1994): The number densities of $\mathrm{SO}_{2}$ were deduced from ion-molecule-reaction mass-spectrometry for various subsonic airliners in December 1991 (DC-9, see Arnold et al., 1992) and July 1993 over Germany. Table 1 lists the original data without fuel flow normalisation. The measured number densities $n$ are converted to dilution ratios using $N=29 \mathrm{EI}_{\mathrm{SO}_{2}} \times 0.8 \times 10^{19} \mathrm{~cm}^{-3} /$ $(64 n)$ according to the mole masses of air and $\mathrm{SO}_{2}$ and the number density of air.

(8) $\mathrm{SO}_{2}$ from Arnold et al. (1996): The data were obtained with the same kind of instrument during the POLINAT-campaigns in 1994 and 1995 (Schumann, 1996b). Because of unknown sulphur content in the aircraft fuels, the emission index may vary between 0.02 and $2 \mathrm{~g} / \mathrm{kg}$. Here, we assume an average emission index of $0.5 \mathrm{~g} / \mathrm{kg}$, which is the mean value of $\mathrm{SO}_{2}$ emission indices measured for the same plume encounters over the North Atlantic (Arnold et al., 1996). Part of the scatter of the resultant dilution ratios may be caused by variations in the fuel sulphur content.
Also, a fraction of the fuel sulphur might be converted to sulphuric acid (Arnold et al., 1994). Although some plumes were encountered several times at different plume ages, the data scatter is too large to identify any systematic trend due to in-plume conversion of $\mathrm{SO}_{2}$ to sulphuric acid.

(9) $\mathrm{H}_{2} \mathrm{O}$ from Busen et al. (1994): The $\mathrm{H}_{2} \mathrm{O}$ concentration increase above ambient values is deduced from measurements with a Lyman- $\alpha$ instrument baselined with a cryogenic hygrometer for measurements within the young $(9 \mathrm{~s})$ DC-9 plume investigated also by Arnold et al. (1992, 1994). The emission index is known within small uncertainties based on an estimated hydrogen mass content of $13.8 \%$ in the fuel. In addition, water vapour concentration data are included as obtained from similar measurements behind the ATTAS test aircraft of type VFW 614 (Schumann et al., 1996).

(10) Temperature increase from Petzold et al. (1997): Temperature was measured in situ with Rosemount platinum resistance thermometers Pt100 and Pt500. One-second mean values were determined from the data during short-distance measurements (plume age $3.4 \mathrm{~s}$ ) behind a Lufthansa Airbus A310-300 during cruise at $10.7 \mathrm{~km}$ altitude over Germany $(\eta=0.283)$. Temperature data are also taken from similar in-situ measurements behind the ATTAS aircraft (Schumann et al., 1996).

(11) Temperature increase: The core jet temperature was measured $1 \mathrm{~m}$ behind the core engine exit cone of the ATTAS at cruise at about $9 \mathrm{~km}$ altitude using non-intrusive Fourier-transform spectroscopy (Haschberger and Lindermeir, 1996, 1997). The 11 individual temperature data measured have a standard deviation of $2 \% \quad(\eta=0.16 \quad$ according to Schumann et al., 1996).

(12) Contrail diameters D (Schumann et al., 1996): Contrails forming behind the ATTAS aircraft were observed at 15-90 $\mathrm{m}$ distance behind the engines. Video observations taken from another aircraft at close distance in relation to the known aircraft dimensions were used to measure the diameters of the two jet engine plumes. The dilution ratio is deduced based on measured fuel flow rates $\left(\dot{m}_{\text {fuel }}=0.16 \mathrm{~kg} \mathrm{~s}^{-1}\right)$, aircraft speed $\left(V=163 \mathrm{~m} \mathrm{~s}^{-1}\right)$ and air density $\left(\rho=0.46 \mathrm{~kg} \mathrm{~m}^{-3}\right)$.

In addition to the measurements, further data were obtained as follows: Stoichiometric combustion of jet fuel with air requires a dilution ratio of 15.7 (Schumann, 1996a). This specifies the minimum dilution within the combuster. The exhaust gases leave the core engine with engine specific dilution ratios ("air/fuel ratio of the engine") of about 50-70 (see Schumann, 1995). The combustion occurs at (estimated) time scales of 1-4 ms. Part of the combustion heat is given by the work of the engine fans to the bypass air stream. For modern engines, the ratio of bypass air mass flux to core air mass flux is between 4 and 6. Hence, the dilution ratio is between 200 and 420 when the exhaust gases from the core engine have mixed with the bypass air. Thereafter, the exhaust 
gases form a jet which mixes with ambient air. The dilution in the jet of typical subsonic engines has been computed for two commercial large jet engines of type CFM56 and RB211 (core exit diameters 656 and $945 \mathrm{~mm}$, used on modern wide-body subsonic aircraft), with two-dimensional models (Louisnard et al., see Schumann, 1995). Related model studies are given in Beier and Schreier (1994), Kärcher et al. (1996), Brown et al. (1996) and Garnier et al. (1997). The dotted curve in Fig. 1 shows results as obtained by large-eddy simulations for dilution in the wake of a B747 (Gerz and Ehret, 1997) at plume ages of 1-300 s (Gerz, personal communication, 1997). These simulations were initialised at $t=1 \mathrm{~s}$ using the jet model of Kärcher et al. (1996). The dilution in the atmospheric dispersion regime under stably stratified atmospheric conditions depends strongly on the amount of shear in the ambient atmosphere. The triangle at plume ages of $400-4000 \mathrm{~s}$ encloses the range of results as obtained by large-eddy simulations for the dispersion of Gaussian plumes at such ages under typical atmospheric conditions (Dürbeck and Gerz, 1996).

\section{DISCUSSION}

Figure 1 compiles data from more than 70 plume encounters with the DLR research aircraft Falcon and the NASA aircraft ER-2. The in-situ concentration measured depends on the flight path of the measuring aircraft relative to the plume axis and the temporal resolution of the instrument. Hence, the measurements give only a rough estimate of the bulk mean concentration. In most cases, the measuring aircraft will have missed the peak concentration positions. This may cause a possibly large overestimate of the dilution ratios. On the other hand, incidental encounters of maximum peak concentrations may result in a relatively small underestimate of the bulk dilution. This explains much of the data scatter. The local dilution ratio (as opposed to the bulk ratio) is a function of radial distance from the plume's axis. Along the axis of the core jet, the dilution ratio is much smaller than for the bulk of the mixed core and bypass jets.

The bulk mean data may be approximated by one interpolating curve

$$
N=7000\left(t / t_{0}\right)^{0.8}, \quad t_{0}=1 \mathrm{~s},
$$

with $t_{0}$ as arbitrary reference scale. Because of the non-Gaussian scatter of the individual data, the fit is based on an estimate. The fit is best for young $(1 \mathrm{~s} \leqslant t \leqslant 50 \mathrm{~s})$ plumes. Individual cases may differ by a factor of about 3-5 from this mean.

It is interesting to see that the data from a wide range of aircraft, including modern medium sized (e.g. B727) and wide-body aircraft (mostly B747) near the tropopause, the supersonic Concorde and the subsonic research aircraft ER-2 in the stratosphere, and the tropospheric research aircraft ATTAS, all fall within the same magnitude range of dilution for given plume age. Within the range of scatter of the data, aircraft plumes seem to mix similarly in terms of fuel-flow specific dilution ratios.

The interpolated dilution ratio values grow slower than linear with time, presumably because stratification reduces the vertical diffusivity more strongly than shear increases the horizontal diffusivity. In the atmospheric dispersion regime, the plume cross-section and the dilution ratio grow non-linearly with time as a function of vertical and horizontal diffusion and of lateral shear distortion of the plume. The increase may follow a square-root, a linear or a quadratic time dependence, depending on which process dominates (Dürbeck and Gerz, 1996). The data used for Fig. 1 were generally taken under conditions with weak ambient turbulence and weak shear, in stably stratified parts of the upper troposphere and lower stratosphere. Much quicker dilution may occur in strongly turbulent events.

The common dilution factor $d$, which measures the plume concentration relative to the core engine exit concentration, is $d(t)=N_{\text {exit }} / N(t)$ with $N_{\text {exit }}$ about 50-70. For a plume age of $4 \mathrm{~s}$ and $N_{\text {exit }}=60$, the result $d=0.0028$ from equation (6) lies between the dilution factors given by Kärcher et al. (1996) for a B747 (0.008, see the $\mathrm{SO}_{2}$ dilution in their Fig. 4), and that of Garnier et al. (1997) for a B767 plume (0.0005).

Lewellen and Lewellen (1996) and Gerz and Ehret (1997) show that the mixing rate $(\mathrm{d} N / \mathrm{d} t) / N$ varies non-monotonically with plume age, as can be seen from the dotted curve in Fig. 1. The mixing rate is large in the initial jet regime, small in the following vortex regime as long as the vortices are stable, increases to large values during the break-up of the vortex flow, and then approaches the asymptotic values in the atmospheric dispersion regime. In terms of the dilution ratio, these variations are within the scatter of the data shown.

The data corroborate the assumption that $\mathrm{NO}_{x}$ may be treated, to first order, as a conservative tracer within the time range considered. Because of uncertain values of the fuel sulphur content and statistical scatter, we cannot evaluate the fraction of $\mathrm{SO}_{2}$ converted to sulphuric acid, but this fraction cannot be very large, because the data follow approximately the same dilution law as other conservative tracers.

Finally, Fig. 2 shows a verification of the dilution law for plume ages from 0.5 to $17 \mathrm{~s}$, based on water vapour and temperature measurements behind the ATTAS aircraft at 8.2 and $9.4 \mathrm{~km}$ altitude over Germany on 15 March 1996, under conditions as described in Petzold et al. (1997). The distance between the ATTAS and the measuring aircraft was measured with differential GPS with an accuracy of better than $8 \% . \mathrm{H}_{2} \mathrm{O}$ was measured with a Lyman- $\alpha$ hygrometer, and temperature with a Rosemount platinum resistance thermometer Pt100. The data were recorded at a rate of $100 \mathrm{~Hz}$. Shown are the results of the peak 


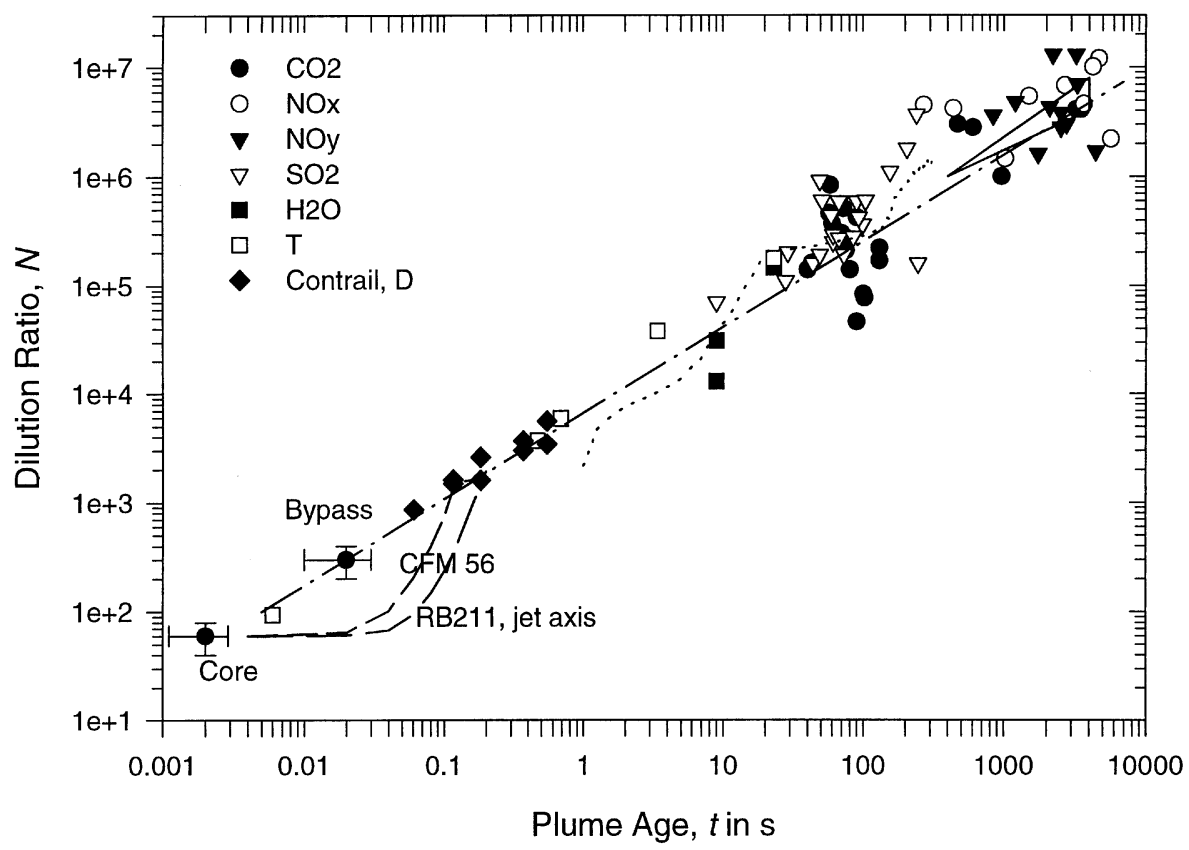

Fig. 1. Dilution ratio versus plume age. The symbols without error bars are derived from measurements. The dots with error bars denote characteristic values for the engine core and bypass exits. The dilution on the jet axis computed for two engines of type CFM56 and RB211 is shown by short and long dashed curves. The dotted curve represents large eddy simulation results of Gerz and Ehret (1997). The triangle at large plume ages denotes the range of dilution values computed by Dürbeck and Gerz (1996). The dash-dotted line is the dilution ratio interpolation $N=7000 t^{0.8}$ (time $t$ in s).

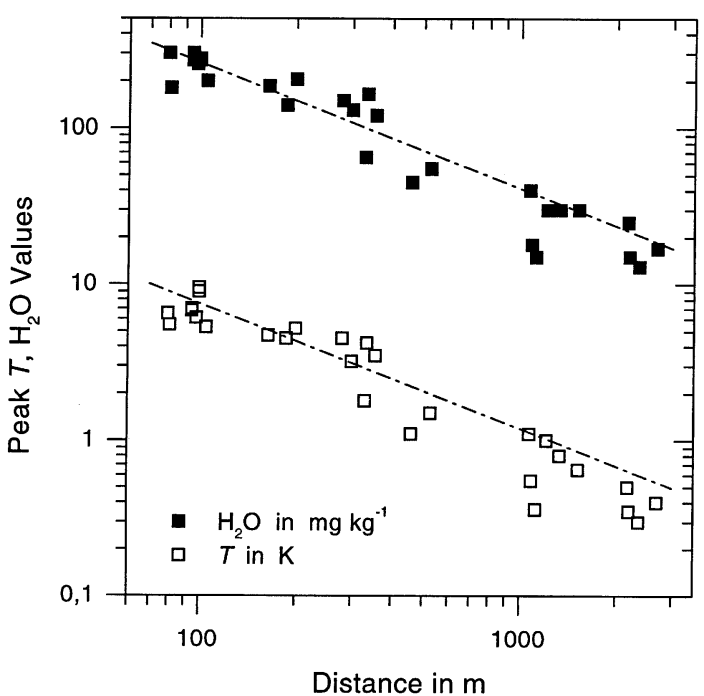

Fig. 2. Water vapour mass concentration and temperature peak values above ambient mean versus distance from the ATTAS aircraft (symbols), and the expected values for given dilution ratio, equation (6) (lines).

values during the measurements within the plume of the ATTAS flying at a speed of $163 \mathrm{~m} \mathrm{~s}^{-1}$, an overall propulsion efficiency of 0.166 , and a water vapour emission index of 1.235. The measured values fit the dilution ratio from equation (6) very well. The data also support the expected correlation between water vapour and temperature fluctuations. The different emissions of heat and water vapour from the core and bypass exit may cause decorrelated temperature and humidity values in the young plume up to 20 core diameters after the engine exit (Schumann et al., 1997). Later, a growing decorrelation originates from wake turbulence and random variations of ambient properties.

\section{CONCLUSIONS}

The dilution of aircraft exhaust has been analysed from measurements in more than 70 plume encounters for plume ages of milliseconds to $95 \mathrm{~min}$. It is found that the bulk dilution ratio for a wide range of conditions can be approximated by equation (6) within a factor of about 3 . The concentration on the plume axis stays about constant until $0.02 \mathrm{~s}$, and then approaches the bulk mean after about $0.3 \mathrm{~s}$, with details depending on engine and flight conditions. Future measurements should try to extend the data base to larger plume ages.

Acknowledgments - The authors are grateful for support by the Deutsche Forschungsgemeinschaft (Schwerpunktprogramm: "Grundlagen der Auswirkungen der Luft- und Raumfahrt auf die Atmosphäre"), the German "Bundesministerium für Bildung, Wissenschaft, Forschung und Technologie (BMBF)" (project "Schadstoffe in der Luftfahrt") and the Commission of the European Union (projects AERO-NOX, POLINAT, and POLINAT-2). 


\section{REFERENCES}

Anderson, M. R., Miake-Lye, R. C., Brown, R. C. and Kolb, C. E. (1996) Calculation of exhaust plume structure and emissions of the ER 2 aircraft in the stratosphere. Journal of Geophysical Research 101, 4025-4032.

Arnold, F., Scheidt, J., Stilp, T., Schlager, H. and Reinhardt, M. E. (1992) Measurements of jet aircraft emissions at cruise altitude I: The odd-nitrogen gases $\mathrm{NO}, \mathrm{NO}_{2}, \mathrm{HNO}_{2}$ and $\mathrm{HNO}_{3}$. Geophysical Research Letters 19, 2421-2424.

Arnold, F., Schneider, J., Klemm, M., Scheid, J., Stilp, T., Schlager, H., Schulte, P. and Reinhardt, M. E. (1994) Mass spectrometric measurements of $\mathrm{SO}_{2}$ and reactive nitrogen gases in exhaust of commercial jet airliners at cruise altitude. Deutsche Forschungsanstalt für Luft- und Raumfahrt Mitteilung 94-06, pp. 323-328.

Arnold, F., Klemm, M., Schneider, J., Bürger, V., DrosteFranke, B., Kirchner, G., Preissler, B., Jung, A. and Dann, W. (1996) Trace gas measurements by aircraft based ion molecule reaction mass spectrometry. Report EUR 16978 EN, Luxembourg: Office for Official Publication of the European Communities, pp. 48-69.

Beier, K. and Schreier, F. (1994) Modeling of aircraft exhaust emissions and infrared-spectra for measurements of nitrogen oxide. Annales Geophysicae 12, 920-943.

Busen, R., Baumann, R., Reinhardt, M. E., Fimpel, H., Kiemle, C. and Quante, M. (1994) Measurements of physical properties in the wake of commercial aircraft. Deutsche Forschungsanstalt für Luft- und Raumfahrt Mitteilung 94-06, pp. 297-302.

Brown, R. C., Miake-Lye, R. C., Anderson, M. R., Kolb, C. E. and Resch, T. J. (1996) Aerosol dynamics in near field aircraft plumes. Journal of Geophysical Research 101, $22,939-22,953$.

Dürbeck, T. and Gerz, T. (1995) Large-eddy simulation of aircraft exhaust plumes in the free atmosphere: effective diffusivities and cross-sections. Geophysical Research Letters 22, 3203-3206.

Dürbeck, T. and Gerz, T. (1996) Dispersion of aircraft exhausts in the free atmosphere. Journal of Geophysical Research 101, 26,007-26,015.

Fahey, D. W. et al. (1995a) In situ observations in aircraft exhaust plumes in the lower stratosphere at mid-latitudes. Journal Geophysical Research 100, 3065-3074.

Fahey, D. W. et al. (1995b) Emission measurements of the Concorde supersonic aircraft in the lower stratosphere. Science 270, 70-74.

Friedl, R. R. (ed.) (1997) Atmospheric effects of subsonic aircraft: Interim assessment report of the advanced subsonic technology program. NASA Refer. Publ. 1400.

Garnier, F., Baudoin, C., Woods, P. and Louisnard, N. (1997) Engine emission alteration in the near field of an aircraft. Atmospheric Environment 31, 1767-1781.

Gerz, T. and Ehret, T. (1997) Wingtip vortices and exhaust jets during the jet regime of aircraft wakes. Aerospace Science Technology 1, 463-474.

Haschberger, P. and Lindermeir, E. (1996) Spectrometric inflight measurement of aircraft exhaust emissions: First results of the June 1995 campaign. Journal of Geophysical Research 101, 25,995-26,006.

Haschberger, P. and Lindermeir, E. (1997) Observation of $\mathrm{NO}$ and $\mathrm{NO}_{2}$ in the young plume of an aircraft jet engine. Geophysical Research Letters 24, 1083-1086.

Karol, I. L., Ozolin, Y. E. and Rozanov, E. V. (1997) Box and Gaussian plume models in the exhaust composition evolution of subsonic transport aircraft in- and out of the flight corridor. Annales Geophysicae 15, 88-96.

Kärcher, B. and Fabian, P. (1994) Dynamics of aircraft exhaust plumes in the jet regime. Annales Geophysicae 12, 911-919.

Kärcher, B., Hirschberg, M. M. and Fabian, P. (1996) Smallscale chemical evolution of aircraft exhaust species at cruising altitudes. Journal of Geophysical Research 101, 15169-15190.

Klemm, O., Schlager, H., Slemr, F., Stockwell, W. R. and Ziereis, H. (1996) Messung der Verteilung flugzeugbedingter Spurengase in der oberen Troposphäre und unteren Stratosphäre. Report No. 38, Fraunhofer-Institut für Atmosphärische Umweltforschung, Garmisch-Partenkirchen, Germany.

Lewellen, D. C. and Lewellen, W. S. (1996) Large-eddy simulations of the vortex-pair breakup in aircraft wakes. A.I.A.A. J. 34, 2337-2345.

Miake-Lye, R. C., Martinez-Sanchez, M., Brown, R. C. and Kolb, C. E. (1993) Plume and wake dynamics, mixing, and chemistry behind a high speed civil transport aircraft. Journal of Aircraft 30, 467-479.

Petzold, A., Busen, R., Schröder, F. P., Baumann, R., Kuhn, M., Ström, J., Hagen, D., Whitefield, P., Baumgardner, A., Arnold, F., Borrmann, S. and Schumann, U. (1997) Near field measurements on contrail properties from fuels with different sulphur content. Journal of Geophysical Research (in press).

Schilling, V., Siano, S. and Etling, D. (1996) Dispersion of aircraft emissions due to wake vortices in stratified shear flows: A two-dimensional numerical study. Journal of Geophysical Research 101, 20,965-20,974.

Schlager, H., Schulte, P., Volkert, H., Busen, R. and Schumann, U. (1994) Observations of enhanced nitric oxide abundances within the North Atlantic flight corridor. Deutsche Forschungsanstalt für Luft- und Raumfahrt Mitteilung 94-06, pp. 336-341.

Schulte, P. and Schlager, H. (1996) In-flight measurements of cruise altitude nitric oxide emission indices of commercial jet aircraft. Geophysical Research Letters 23, 165-168.

Schulte, P., Schlager, H., Ziereis, H., Schumann, U., Baughcum, S. and Deidewig, F. (1997) $\mathrm{NO}_{x}$ emission indices of subsonic long-range jet aircraft at cruise altitude: In situ measurements and predictions. Journal of Geophysical Research 182, 21,431-21,442.

Schumann, U. (1994) On the effect of emissions from aircraft engines on the state of the atmosphere. Annales Geophysique 12, 365-384.

Schumann, U. (ed.) (1995) AERONOX - The impact of $\mathrm{NO}_{x}$ emissions from aircraft upon the atmosphere at flight altitudes 8-15 km. Report EUR 16209 EN, Brussels: European Commission, DG XII, and DLR Cologne, ISBN-92-826-8281-1, p. 471.

Schumann, U. (1996a) On conditions for contrail formation from aircraft exhausts. Meteorologische Zeitschrift 5, $4-23$.

Schumann, U. (ed.) (1996b) Pollution from aircraft emissions in the North Atlantic flight corridor (POLINAT). Report EUR 16978 EN, Luxembourg: Office for Official Publication of the European Communities, p. 303.

Schumann, U. (1997) The impact of nitrogen oxides emissions from aircraft upon the atmosphere at flight altitudes - results from the AERONOX project. Atmospheric Environment 31, 1723-1733.

Schumann, U., Konopka, P., Baumann, R., Busen, R., Gerz, T., Schlager, H., Schulte, P. and Volkert, H. (1995) Estimate of diffusion parameters of aircraft exhaust plumes near the tropopause from nitric oxide and turbulence measurements. Journal of Geophysical Research 100, $14,147-14,162$.

Schumann, U., Ström, J., Busen, R., Baumann, R., Gierens, K., Krautstrunk, M., Schröder, F. P. and Stingl, J. (1996) In situ observations of particles in jet aircraft exhausts and contrails for different sulphur containing fuels. Journal of Geophysical Research 101, 6853-6869.

Schumann, U., Dörnbrack, A., Dürbeck, T. and Gerz, T. (1997) Large-eddy simulation of turbulence in the free atmosphere and behind aircraft. Fluid Dynamics Research 20, $1-10$. 